\title{
How Does Tie Strength Dispersion within Inter-Organizational Networks Affect Agricultural Technological Innovation? Evidence from China
}

\author{
Long Cheng ${ }^{1}$, Shiyuan Zhang ${ }^{1}$, Xuming Lou ${ }^{1}$, Jie Huang ${ }^{2}$, Fangping Rao ${ }^{3, *}$ and Rui Bai ${ }^{1}$ \\ 1 School of Economics and Management, Xi'an University of Posts and Telecommunications, \\ Xi'an 710061, China; chenglong@xupt.edu.cn (L.C.); zsy1226@stu.xupt.edu.cn (S.Z.); \\ louxuming@xupt.edu.cn (X.L.); brr@stu.xupt.edu.cn (R.B.) \\ 2 School of Management, Xi'an Jiaotong University, Xi'an 710061, China; 3119426074@stu.xjtu.edu.cn \\ 3 School of Public Administration, Nanjing University of Finance \& Economics, Nanjing 210023, China \\ * Correspondence: fangpingrao@nufe.edu.cn
}

check for updates

Citation: Cheng, L.; Zhang, S.; Lou, X.; Huang, J.; Rao, F.; Bai, R. How Does Tie Strength Dispersion within Inter-Organizational Networks Affect Agricultural Technological Innovation? Evidence from China. Land 2021, 10, 717. https://doi.org/ 10.3390/land10070717

Academic Editors: Assem Abu Hatab, Nasem Baderldin and Zhen Liu

Received: 25 May 2021

Accepted: 4 July 2021

Published: 7 July 2021

Publisher's Note: MDPI stays neutral with regard to jurisdictional claims in published maps and institutional affiliations.

Copyright: (c) 2021 by the authors. Licensee MDPI, Basel, Switzerland. This article is an open access article distributed under the terms and conditions of the Creative Commons Attribution (CC BY) license (https:/ / creativecommons.org/licenses/by/ $4.0 /)$.

\begin{abstract}
Agricultural technology is key to ensuring food security. Innovation in agricultural technology plays a vital role in increasing national food production. Collaborative innovation has become an essential form of technological innovation in the new era. Although there has been a large body of literature exploring the influencing factors on technological innovation, how tie strength dispersion within inter-organizational networks affects agricultural technological innovation has not been systematically studied. In this research, we use a cooperative network to investigate how relational divisive faultlines caused by the uneven distribution of the strength of inter-organizational relationships affects agricultural technological innovation through the subgroup structure, and the moderating role of position embeddedness. This article uses the Derwent Innovations Index to select agricultural technology joint patent applications from 2000 to 2018 to build a cooperation network, and uses multiple linear regression to conduct an empirical analysis. The empirical results show that the relational divisive faultlines have a positive effect on the subgroup structure. There is an inverted U-shaped relationship between the subgroup structure and agricultural technological innovation. The initial stage of subgroup formation can transmit the information between the subgroups in time and promote the efficiency of agricultural technological innovation. However, as the degree of subgroup cohesion increases, the phenomenon of "in-group" and "out-of-group" will be formed, which will inhibit information exchange, having a negative impact on agricultural technological innovation. In addition, positional embeddedness has a significant positive moderating effect between relational divisive faultlines and agricultural technological innovation. This research provides a theoretical basis for understanding how the overall network relationship strength distribution affects technological innovation by exploring the micro-process of the structural changes of the cooperation network. Moreover, it has specific guiding significance for the organization to participation in a cooperation network to improve the efficiency of agricultural technological innovation.
\end{abstract}

Keywords: agricultural technology; divisive faultlines; subgroup structure; innovation network

\section{Introduction}

Agriculture is the foundation of the national economy and the cornerstone of social stability and economic development. Since the founding of New China, the Communist Party of China and the country have attached great importance to food safety production [1] In recent years, China's grain harvest has been very productive, and grain output has stabilized at more than 1.3 trillion catties for six consecutive years. According to data from the National Bureau of Statistics of China, China's total grain output in 2019 was 663.84 million tons, an increase of 5.94 million tons over the previous year, and an increase of $0.9 \%$ year-on-year, which is a record high [2]. However, under China's national condition 
of more people and less land, and with a continuous increase in Chinese residents' food consumption level and demand for high-quality food, China's food gap has long existed and will expand further. Making up for the shortcomings of the domestic food quality is the key to improving China's food security.

As primary productive forces, science and technology are the keystones of various fields of social development and human progress, and have an important influence on agriculture, especially food security. Over the years, China's grain output per unit area has been lower than the United States. The main reason for this is insufficient investment in science and technology and the low level of large-scale agricultural production and mechanization. Developing agricultural technological innovation and promoting the application of key information technology in the agricultural field can significantly increase agricultural productivity. Agriculture is different from manufacturing and high-tech industries. It has unique characteristics in the form of industrial agglomeration and technological innovation. Breaking through the traditional small peasant economy and building a new carrier for the agricultural industry has far-reaching strategic significance for furthering the implementation of the agricultural revitalization strategy. Cooperative innovation in a networked environment has become an important form of technological innovation in the new era. Multiple companies or organizations form a network through cooperation, and a collaborative network composed of multiple organizations is like a vast knowledge pool. It can provide an important foundation for firms to access new knowledge for technological innovation.

With the increasing openness of the innovation ecosystem, the innovation network has become more and more complex. It presents the loosely coupled characteristics of overall unity and partial module independence [3]. Network members choose their partners according to different preferences. There may be different degrees of trust and different relationships with each other, leading to an uneven distribution of partnerships in the innovation network. The uneven distribution of the strength of the node's binary relationship in the cooperative network will cause some closely cooperative organizations to form subgroups with strong cohesion [4].

Some scholars have realized the performance of the subgroup phenomenon in the inter-organizational cooperation network and have studied the formation of subgroups from the perspective of an inter-organizational relationship, using this to explain the reason for the formation of the subgroups. Lau and Murnighan proposed that when the relationship strength is different among different member pairs, the difference in relationship strength enhances the possibility of group division, further creating trust issues and the formation of cohesive subgroups. This creates the problem of the cohort belonging "within the group" or "outside the group" [5]. Thatcher and Patel called on scholars to explore divisive faultlines by researching alliances and social networks [6]. Later, when studying the stability of multilateral alliances, some scholars extended the concept of divisive faultlines between individuals to the inter-organizational level [4]. It is believed that the uneven distribution of the strength of relationships between organizations will lead to differences in the degree of cooperation and sharing of experiences, making the overall cooperation network produce potentially divisive faultlines and further divide into multiple factions. The study regards divisive faultlines as the distribution of the strength of the dual relationship between organizations at the overall network level. Its essence is the difference in the degree of shared experience between partners. That is, the unbalanced state of relationship strength is caused by the difference in the degree of cooperation between different organizations. This state will lead to the formation of strong, cohesive subgroups among companies that cooperate closely. Companies with weak partnerships are excluded from the cohesion subgroup [7].

In a cooperation network, when a specific firm holds the dominant resources and advantages, the firm often forms a focal firm, which provides the necessary governance and discipline for the network members to achieve the overall goal $[8,9]$. Positional embeddedness makes the network form a network structure between the center and the periphery. 
Shipilov believes that companies in the brokerage position often choose partners in different positions according to the degree of realization of their performance vision. When the performance vision deviates from the original expectations, the brokerage company will change the partner selection strategy [10]. It will then choose a partner close to its status. Therefore, we have reason to believe that firms occupying a central position will have a particular impact on the firms' technological innovation in a cooperative network.

This article integrates divisive faultlines and social network theories and explores the relationship between inter-organizational cooperation network relational divisive faultlines, subgroup structures, positional embeddedness, and agricultural technological innovation. Data was collected to analyze how the relational divisive faultlines affect agricultural technological innovation. We provide theoretical references and suggestions for improving technological innovation performance. This article mainly studies the following issues: (1) the influence of relational divisive faultlines on the subgroup structure; (2) the influence of the subgroup structure on agricultural technological innovation; and (3) the moderating effect of positional embeddedness between relational divisive faultlines and agricultural technological innovation.

\section{Model Construction and Hypothesis}

Lau and Murnighan define faultlines as "an assumed dividing line that divides a group into two or more subgroups based on one or more attributes (an individual's demographic characteristics, such as race, gender, nationality, and age, etc.)" [11]. Faultline theory believes that similarity can promote social identity between individuals and make individuals choose to form alliances with members that are similar to themselves [12]. Heidl extends the concept of faultlines from inter-individual groups to the level of inter-organizational groups (multilateral alliances). From the perspective of strategic management, the nature of faultline generation is analyzed. It believes that group members form cohesive subgroups based on common experience and mutual identification [4]. This article proposes the term "divisive faultlines" from the perspective of relationship embeddedness. Since the technological innovation network is a relatively loose cooperative network, there are sparse cooperative relations among network members. It believes that divisive faultlines are a concept related to the distribution or configuration of the relationship strength between firms. It is essentially caused by the difference in the degree of shared experience between firms. These experiences can be shared indirectly (similar members may have similar experiences). It can also be shared directly through the interactions of history.

The trust mechanism established between members forms a technological innovation network through the development of multiple relationships. It can increase expectations of reciprocity and reduce concerns about justice and fairness. Additionally, it can encourage partners to share information further to strengthen the binding between firms [12]. When members of the network maintain and strengthen the dual relationship with specific members, they will inevitably ignore the relationship with other members. When the strength of the relationship is distributed differently between different pairs of members, certain members maintain strong relationships with some and weak relationships with others. The existence of differences in relationship strength generates trust issues and results in cohesive subgroups being formed. Eventually causing the problem of a cohort belonging "within the group" or "outside the group" [11]. This leads to the formation of multiple factions in the overall network [13].

The existence of divisive faultlines causes the overall network to be divided into different subgroups in the agricultural technological innovation ecosystem. Inter-firm cooperation is an important way to improve network cooperation and innovation performance. It is not difficult for us to explore this. The formation of a camp has a particular impact on the performance of network cooperative innovation. The cooperation between firms within the camp becomes closer, and members in each camp cooperate is relatively loose. At the same time, the focal firms within each camp play a key role in promoting the formation of the camp and network changes. The more prominent the competition, the 
more pronounced the boundaries of its camp, in other words. By occupying the central position in the network, focal firms will intensify the formation and development of the camp. Therefore, we believe that the higher the member position embeddedness, the stronger the relationship between the divisive faultlines and the formation of subgroups.

\subsection{Model Construction}

The participation of firms in an inter-organizational cooperation network has become one of the essential ways to enhance the potential of technological innovation. However in practice, network members are not entirely interconnected. In other words, members of an inter-organizational network do not need to have a cooperative relationship with all the members of the network. Only some specific partners are selected for cooperation, leading to the existence of local tight sub-networks [14]. In this article, we discuss the influence of relational divisive faultlines on the structure of subgroups due to the uneven distribution of binary relations among organizations in cooperative networks. We also look at how the subgroup structure produced by the relational divisive faultlines affects the network operation in the cooperative network. Is there a conditional mechanism in the process of relational divisive faultlines affecting the cooperative network? We try to solve these problems. In this article, technological innovation represents the result of cooperation network operation, and the concept of the "faultlines-subgroup-result" model construction in faultlines-related literature is followed. The main research contents are as follows:(1) the direct influence of relational divisive faultlines on subgroup structure; (2) the direct influence of subgroup structure on technological innovation; and (3) the moderating role of position embeddedness between relational divisive faultlines and the subgroup structure. The conceptual model is shown in Figure 1.

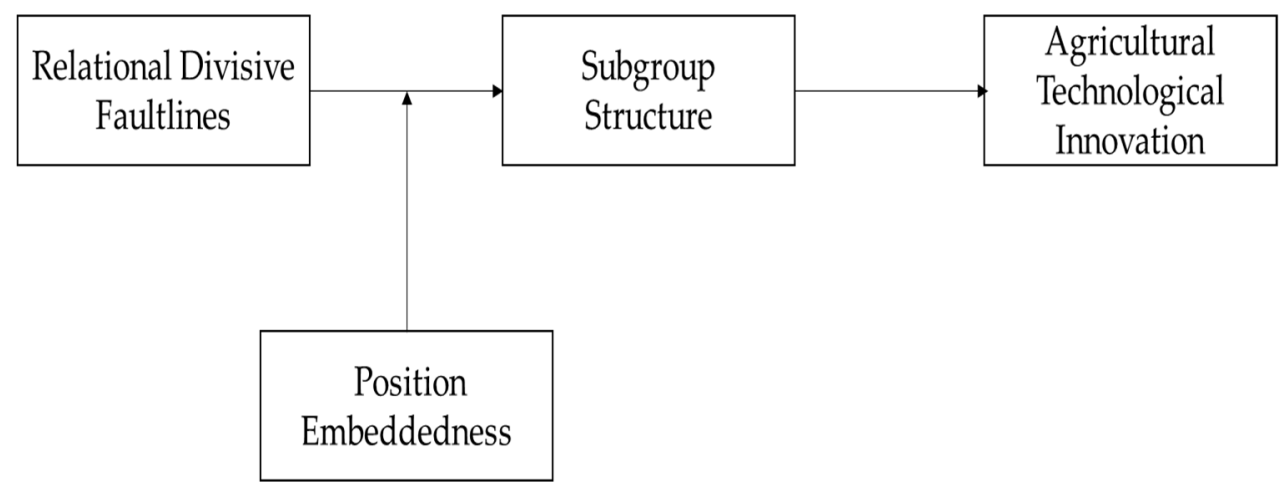

Figure 1. Conceptual Model of this Article.

\subsection{Hypothesis}

2.2.1. Relational Divisive Faultlines and Subgroup Structure

Relational divisive faultlines occur because the choice of partners between firms depends largely on historical partnerships. Firms will give priority to cooperation with partners who they have had direct or indirect relationships with in the past. This leads to differences in the degree of experience sharing between companies [4]. First, when the strength of the relationship between members of the network is unevenly distributed, there are differences in the degree of experience sharing among firms. When this difference creates different degrees of trust and relationships between partners, the network may become divided into multiple subgroups in the process of cooperation in the agricultural technological innovation network. The company has no need to maintain strong relationships with all network members. While a company maintains a strong relationship with some specific partners, it can only maintain a weak relationship with other partners. This strong relationship will limit the establishment of new and more inclusive norms involving a more comprehensive range of partners [15]. 
Second, when the distribution of the strength of the relationships between firms is very uneven, there will be strong divisive faultlines. At this time, firms with a high degree of experience sharing share common values, norms, and mutual trust are connected through close relationships to form cohesive local subgroups, while the rest of the firms are queued outside the subgroups. Because the members of the subgroup trust the members of that group more, it will make the members outside the subgroup feel the unfairness of the cooperation, reduce cooperation expectations, or even reduce the current cooperation and withdraw completely [16]. This kind of in-group and out-of-group dispute can cause mistrust among members belonging to different subgroups. It causes the relationship within the subgroup to be strong, and the relationship between subgroups to be weak [17]. In addition, when the strength of the divisive faultlines is greater, the flow of knowledge between subgroups is more restricted, and the distrust and inequality between subgroups are further magnified [7]. The stronger the uneven distribution of the strength of relationships between firms, the higher the degree of difference in experience sharing. The resulting relational divisive faultlines are stronger, and the boundaries between subgroups and subgroups is clearer. Therefore, this article proposes the following hypothesis:

Hypothesis 1: The relational divisive faultlines caused by the distribution of inter-organizational relations positively affects the subgroup structure.

\subsubsection{Subgroup Structure and Agricultural Technological Innovation}

The agricultural technological innovation network is a relatively loose and sparsely connected firm cooperation network. The overall network cohesion is not strong. The formation of a subgroup structure can strengthen the local cohesion of the network to a certain extent, which is very important for the promotion of agricultural technological innovation. Specifically, when the subgroup phenomenon is not evident in the network, it is difficult to generate consensus and mutually recognized cooperation norms between firms, which is not conducive to the absorption of mutual knowledge during cooperation between firms. The relatively sparse relationship between network members is also not conducive to reciprocity between firms and will hinder knowledge sharing between firms. With the gradual aggregation of network subgroups, the strong relationships between the subgroups will promote the frequency of cooperation between firms. This is conducive to establishing a robust trust mechanism between firms and to the improvement of knowledge sharing and absorption. At the same time, an appropriate level of relationship between the subgroups will introduce the heterogeneous knowledge and resources of different subgroups, and through this strong interaction between the subgroup members, the knowledge and resources can be digested and absorbed, and effectively combined. In other words, the knowledge heterogeneity of different subgroups depends on the degree of connection between the subgroups [18], and this further improves the efficiency of technological innovation in agricultural firms. In addition, this article believes that the subgroup structure has also negatively affected agricultural technological innovation. That is, the formation of the subgroup structure has a certain inhibitory effect on cooperation between subgroups because the knowledge between firms in the same subgroup may have similarities. The heterogeneity of corporate knowledge among different subgroups is substantial. As cohesion within the subgroup increases, the members of the subgroup are locked in by the initial partner selection. This prevents internal members from cooperating with companies from competing groups through the loyalty expectations of members [19], thereby blocking opportunities for firms to establish cooperation with outside partners, thus reducing the intensity of knowledge transfer, transaction, and absorption between subgroups.

On the whole, the initial stage of subgroup cohesion will be conducive to overall agricultural technological innovation because the combination of cohesion within subgroups and the bridging relationship between subgroups can transfer knowledge and information between subgroups in time. However, as the degree of cohesion of subgroups increases, the subgroup structure has a particular inhibitory effect on the cooperation between agricul- 
tural firms, which negatively impacts on agricultural technological innovation. Therefore, this article proposes the following hypothesis:

Hypothesis 2: The subgroup structure and agricultural technological innovation are in an inverted U-shaped relationship.

2.2.3. The Moderating Role of Position Embeddedness on the Relational Divisive Faultlines and Subgroup Structure

Position embeddedness is an important mechanism that affects the formation of relationships between firms. Firms occupying the central position of a network have competitive advantages in many aspects. Position embeddedness can aggravate the uneven distribution of relationship strength in the network from the following aspects. First, the information advantages of centrally located companies make them more attractive [19]; this attraction contributes to the cohesion of network members [20]. Secondly, the reputation advantage of a centrally located company makes it more reliable, and the role of social supervision reduces opportunistic behavior and maintains cooperation [4]. Finally, the power advantage of a centrally located company gives it the ability to influence and control the relationships between other network members [21,22]. Through the three functions of the implementation of "joint promotion" brokerage behavior, the coordination, and the governance of the relationship between firms, centrally located firms can make the cooperative relationship between firms around them closer. This strengthens the stability of the central/peripheral network structure. The higher the degree of dispersion of position embeddedness, the more likely the formation of multiple cohesive subgroups is with a central/peripheral network structure in a technological innovation network because of the governance role of the focal firm. The central position strengthens the cooperative relationship between firms and maintains the stability of the subgroups. On the contrary, if the position embedding in the network is very concentrated, this shows that the number of relationships among firms is relatively evenly distributed. At this time, it will be difficult to produce a suitable coordinator, and the opportunity cost of network members to withdraw from cooperation will also be reduced. Therefore, in the case of highly discrete position embedding, it is easier to form a subgroup centered on a centrally located company that is composed of strong relationships. Multiple companies in similar central positions are stabilizing their respective subgroups at the same time. The connection between subgroups tends to be broken. The highly discrete nature of the network position strengthens the influence of the relational divisive faultlines on the structure of the subgroups. Therefore, this article proposes the following hypothesis:

Hypothesis 3: Position embeddedness will adjust the influence of relational divisive faultlines on the subgroup structure. As the degree of dispersion of the overall network position embedding increases, the relational divisive faultlines have a stronger positive effect on forming the subgroup structure.

\section{Empirical Study Design}

\subsection{Data and Sample}

The Derwent patent index database (hereinafter referred to as the Derwent database) is an essential database of global patent resources launched by Thomson Reuters. It collects patent information from 41 patent-accepting agencies worldwide. It is an important channel and tool for many scholars to analyze technological innovation in necessary materials or critical fields. For example, Che analyzed important patent information from the wind energy industry based on Derwent's manual code. It included leading firm technological innovation and product development information and technological comparison information among leading firms [23]. Agricultural technology is the first driving force of agricultural development and the key to food security. In this study, to promote agricultural technological innovation, agricultural technology patents were searched according to the International Patent Classification (IPC) principle. The principle of IPC includes department, division, major category, minor category, major group, and 
small group; first of all, it is divided into categories. A01 includes agriculture, forestry, animal husbandry, hunting, trapping, and fishing. Second, it is divided according to subcategories. Finally, choose agricultural technology, including A01B, A01C, A01D, and A01F, to search for patents, and download the 2000-2018 agricultural technology patents through the Derwent Innovations Index. Use the data of joint applications for invention patents between firms to build a network of cooperation between organizations. Select the number of joint applications for invention patents between organizations from 2000 to 2018. Exclude universities, research institutes, and other organizations. Combine and encode data.

In the processing of longitudinal data, the method of establishing a time window to reflect the network is usually adopted. Refer to previous research in [7,24]. This article establishes a 5-year mobile time window. Dividing the 2000-2018 data into 14 5-year time windows reflects the technological innovation network. Namely, 2000-2004 (corresponding to the 2005 observation period), 2001-2005 (corresponding to the 2006 observation period), etc., up to 2014-2018 (corresponding to the 2019 observation period). It is used to reflect the 14 observation periods from 2005 to 2019 in this article as the overall technological innovation network is relatively loose. UCINET6.0 software is used to divide the network boundary further. This article obtained a total of 221 technological innovation network samples. The final network number and node distribution of each sub-industry are shown in Table 1.

Table 1. Network Number and Node Distribution of Each Sub-Industry.

\begin{tabular}{ccccc}
\hline Industry Category & Number of Networks & Minimum Network Size & Maximum Network Size & Average Network Size \\
\hline A01B & 41 & 4 & 10 & 6 \\
A01C & 110 & 4 & 42 & 8 \\
A01D & 53 & 4 & 14 & 6 \\
A01F & 17 & 4 & 7 & 5 \\
\hline
\end{tabular}

\subsection{Measures}

Variable

Agricultural technological innovation: following the research of Chemmanur and Tian, patents are used to measure innovation $[25,26]$. This article uses the logarithm of agricultural invention patents to measure agricultural technological innovation [27].

Relational divisive faultlines: this article draws on Gibson, Vermeulen, and Heidl's relational divisive faultlines [28] with the relationship-type divisive faultlines being measured by the discreteness of the strength of the binary relationship in the overall network. First, the year is taken as the unit. The duration of the relationship is used to measure the embeddedness of historical relationships [29] according to a 5-year time window. The historical relationship strength of the member pair $(\mathrm{k})$ in the time window $(\mathrm{t})$ is the sum of the duration of the relationship in the past 5 years ( $t-5$ to $t-1)$. The specific calculation steps are as follows.

First, assign a value to the strength of the relationship and determine the strength of the relationship between the pair of members according to the duration of the relationship. If the relationship between the pair of members only exists for 1 year, assign a value of 1 to the strength of the relationship in the first year, and its historical relationship strength is 1 . If the historical relationship between a member pair lasts for 2 years, assign a value of 2 to the strength of the relationship in the second year, and its historical relationship strength is $1+2$, and so on. If the relationship between member pairs lasts for 5 years, assign a value of 5 to the strength of the relationship in the fifth year, and its historical relationship strength is $1+2+3+4+5$. According to this method, the value range of historical relationship strength between member pairs is $0-15$. Second, calculate the standard deviation of the historical relationship strength between all member pairs in each time window. In this way, the dispersion of the strength of the historical relationship within the time window is measured. A standard deviation of 0 indicates that the relationship strength distribution 
between multiple member pairs is uniform, and the network relationship-type divisive faultline strength is low. The larger the standard deviation indicates that the historical relationship strength is concentrated in a subset of a few member pairs and the higher the strength of the network relationship divisive faultlines.

Subgroup structure: the structure of agglomerated subgroups is expressed in the number of subgroups [30]. Cliques are often seen as an essential tool for analyzing the structure of subgroups in social network analysis [31]. A clique refers to the most extensive complete subgraph containing three points. However in reality, the technological innovation network is relatively sparse [32]; therefore, this article uses N-clique to divide subgroups. N-clique refers to the faction, and the maximum distance between any two points in the network does not exceed $\mathrm{N}$. The best critical point is recognized as $\mathrm{N}=2$. This article uses the ratio of the number of members of the technological innovation network (network size) and the amount of two-clique subgroups in the network to measure the subgroup structure:

$$
\text { Subgroup Structure }=\frac{\text { Network Size }}{\text { Number of Subgroups }}
$$

Position embeddedness: centrality is a commonly used index to measure network position in network structure research. This article uses degree centrality to measure the network position of a firm [3]. The greater the degree of centrality of a firm, the more central the firm is in the network, by calculating the standard deviation of the degree centrality of all firm nodes. This can reflect the discrete degree of position embedding in the network. The specific calculation steps are as follows. First, for all members of a particular observation network, measure the degree centrality of all members from $t-5$ to $\mathrm{t}-1$. Second, by calculating the standard deviation of the centrality of all membership degrees, the position embedding dispersion of the overall network is expressed.

This article refers to existing research to select relevant control variables, ensuring the accuracy of experimental results.

Network size: the larger the network scale, the greater the coordination cost, monitoring cost, and management complexity among members [33]. Therefore, this article controls the network scale by calculating the number of members in the network.

Network density: a densely connected network produces collective cohesion, forms reciprocal norms, and restricts independent behavior [34]. Therefore, under the same network scale, the greater the network density, the closer the connections between members. The calculation formula is as follows:

$$
\text { Density }=\frac{2 L}{g(g-1)}
$$

where $L$ is the actual relationship number in the network, and $g$ is the number of nodes in the network. Density indicates the ratio of the actual relationship number of the network to all possible relationship numbers in the period $t-5$ to $t-1$, and the value range is $(0,1)$.

Average relationship strength: the strong dual relationship between firms is conducive to strengthening trust and reducing the risk of opportunism. Therefore, the technological innovation network composed of dense and robust relationships has strong social cohesion. The formation of collective reciprocity norms will restrict the behavior of network members [34]. With regards to Heidl's research, this article controls the cohesion caused by this dense and strong relationship by considering the average relationship strength [4]. There are two main steps to measure the average relationship strength: the first step is to calculate the historical relationship strength of members to $\mathrm{k}$ at time $\mathrm{t}$ according to a 5-year time window. The second step is to calculate the sum of the historical relationship strengths of all member pairs and divide by the number of member pairs.

\subsection{Empirical Model}

To verify Hypothesis 1 , set the following model:

Subgroup Structure $_{t}=\alpha+\beta_{1}$ Relational Divisive Faultines $_{t-1}+\sum_{j=1}^{4} \partial_{j} *$ Control $_{t-1}^{(j)}+\varepsilon_{t-1}$ 
To verify Hypothesis 2, set the following model:

Agricultural Technological Innovation $t_{t}=\alpha+\beta_{1}$ Subgroup Structure $_{t-1}+\beta_{2}$ Subgroup Structure $_{t-1}{ }^{2}+$

$$
\sum_{j=1}^{4} \partial_{j} * \text { Control }_{t-1}^{(j)}+\varepsilon_{t-1}
$$

To verify Hypothesis 3, set the following model:

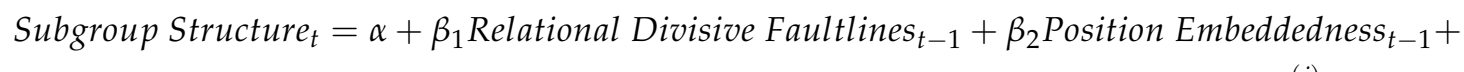
$\beta_{3}$ Position Embeddedness $_{t-1} *$ Relational Divisive Faultlines $t_{t-1}+\sum_{j=1}^{4} \partial_{j} *$ Control $_{t-1}^{(j)}+\varepsilon_{t-1}$

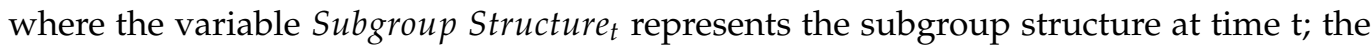
variable Relational Divisive Faultines ${ }_{t-1}$ represents the strength of the network divisive faultlines at $\mathrm{t}-1$; the variable Agricultural Technological Innovation t $_{t}$ represents the agricultural technological innovation at time $\mathrm{t}$; Control represents the control variable network size, network density, average relationship strength, and several subgroups; and $\varepsilon_{\text {it }}$ represents a random disturbance item that has nothing to do with the explanatory variable.

\section{Empirical Results}

\subsection{Descriptive Statistics}

This article uses STATA 15.1 software for descriptive statistical analysis. Table 2 lists the descriptive statistical results of all variables involved in this article, including sample size, mean, median, standard deviation, and maximum and minimum values.

Table 2. Descriptive Statistics of Measured Variables.

\begin{tabular}{|c|c|c|c|c|c|c|}
\hline Variable & $\mathbf{N}$ & Mean & p50 & sd & Max & Min \\
\hline Agricultural Technological Innovation & 221 & 15.670 & 10.000 & 16.810 & 114.000 & 1.000 \\
\hline Relational Divisive Faultlines & 221 & 24.620 & 5.357 & 67.610 & 468 & 0.250 \\
\hline Subgroup Structure & 221 & 3.668 & 4.000 & 1.386 & 14.000 & 1.750 \\
\hline Position Embeddedness & 221 & 2.827 & 2.199 & 2.230 & 16.88 & 0.000 \\
\hline Network Density & 221 & 0.696 & 0.450 & 0.942 & 6.833 & 0.043 \\
\hline Network Size & 221 & 6.842 & 5.000 & 5.971 & 42.000 & 3.000 \\
\hline Average Relationship Strength & 221 & 2.161 & 1.800 & 1.418 & 10.80 & 1.000 \\
\hline Number of Subgroups & 221 & 2.176 & 1.000 & 2.322 & 16.000 & 1.000 \\
\hline
\end{tabular}

\subsection{Correlation Analysis}

Table 3 shows the Pearson correlation analysis results. It can be seen from Table 3 that the correlation coefficients between variables are all less than 0.7 . This shows that there is no strong correlation between variables and avoids possible multicollinearity problems.

Table 3. Correlation Table of Measured Variables.

\begin{tabular}{cccccccc}
\hline Variable & $\mathbf{1}$ & $\mathbf{2}$ & $\mathbf{3}$ & $\mathbf{4}$ & $\mathbf{5}$ & $\mathbf{6}$ & $\mathbf{7}$ \\
\hline Agricultural Technological Innovation & 1 & & & & & & \\
Relational Divisive Faultlines & $-0.064^{* *}$ & 1 & & & & & \\
Subgroup Structure & 0.003 & 0.024 & 1 & & & & \\
Position Embeddedness & $0.331^{*}$ & $0.015^{*}$ & $0.255^{*}$ & 1 & & & \\
Network Density & -0.132 & $0.328^{*}$ & 0.104 & $0.466^{*}$ & 1 & & \\
Network Size & $0.675^{*}$ & $-0.080^{* *}$ & -0.103 & $0.141^{*}$ & $-0.239^{*}$ & 1 & \\
Average Relationship Strength & $0.023^{* *}$ & $0.268^{* * *}$ & 0.111 & $0.672 *$ & $0.545^{*}$ & $-0.139^{*}$ & 1 \\
Number of Subgroups & $0.638^{*}$ & -0.082 & $-0.356^{*}$ & 0.055 & $-0.248^{*}$ & $0.952^{*}$ & $-0.157^{*}$ \\
\hline
\end{tabular}

Notes: ${ }^{* * *}, * *$, and $*$ represent $p<0.01, p<0.05$, and $p<0.1$, respectively.

\subsection{Regression Analysis}

This part uses empirical methods to construct regression models to test the hypotheses put forward by the research. When testing the moderating effect, the article uses multiple linear regression methods to test the hypotheses. This method is widely used in the orga- 
nization and management literature $[35,36]$. In the test of regulation, we used the most commonly used modulated multiple regression to test the moderating effect. When the independent variables and regulatory variables are continuous variables, the independent variables and regulatory variables are standardized first, and then the product term is constructed. The reason for this is that independent variables and moderators are often highly correlated with their interaction terms. The study established five sub-models: Model 1 only verifies the influence of control variables such as network size on the subgroups structure; Model 2 examines the direct influence of relational divisive faultlines on the subgroups structure; Model 3 only verifies the influence of control variables such as network scale on agricultural technological innovation; Model 4 examines the influence of subgroup structure on agricultural technological innovation; and Model 5 examines the moderating effect of position embeddedness. The regression results are shown in Table 4 .

Table 4. Results of Regression Analysis.

\begin{tabular}{|c|c|c|c|c|c|}
\hline & $\begin{array}{l}\text { Subgroup } \\
\text { Structure }\end{array}$ & $\begin{array}{l}\text { Subgroup } \\
\text { Structure }\end{array}$ & $\begin{array}{c}\text { Agricultural } \\
\text { Technological Innovation }\end{array}$ & $\begin{array}{c}\text { Agricultural } \\
\text { Technological Innovation }\end{array}$ & $\begin{array}{l}\text { Subgroup } \\
\text { Structure }\end{array}$ \\
\hline Number of Subgroups & $\begin{array}{l}-0.755^{* * *} \\
(-11.01)\end{array}$ & $\begin{array}{l}-0.753 * * * \\
(-11.02)\end{array}$ & $\begin{array}{c}3.845^{* * *} \\
-6.02\end{array}$ & $\begin{array}{c}6.412 * * * \\
-8.71\end{array}$ & $\begin{array}{l}-0.690 * * * \\
(-9.77)\end{array}$ \\
\hline Network Density & $\begin{array}{l}0.322 \\
-1.02\end{array}$ & $\begin{array}{r}0.252 \\
-0.8\end{array}$ & $\begin{aligned}- & 14.712 * * * \\
& (-5.01)\end{aligned}$ & $\begin{array}{l}-15.833 * * * \\
(-5.84)\end{array}$ & $\begin{array}{l}1.245^{* * *} \\
-2.73\end{array}$ \\
\hline Network Size & $\begin{array}{l}-2.959 * * * \\
-7.93\end{array}$ & $\begin{array}{l}2.923 * * * \\
-7.86\end{array}$ & $\begin{array}{l}4.761 \\
-1.37\end{array}$ & $\begin{array}{l}-6.025 \\
(-1.65)\end{array}$ & $\begin{array}{l}2.664^{* * *} \\
-6.93\end{array}$ \\
\hline Average Position Embeddedness & $\begin{array}{l}0.114 \\
-1.44\end{array}$ & $\begin{array}{c}0.13 \\
-1.65\end{array}$ & $\begin{array}{l}1.624 * * \\
-2.21\end{array}$ & $\begin{array}{c}1.223^{*} \\
-1.8\end{array}$ & $\begin{array}{l}-0.01 \\
(-0.11)\end{array}$ \\
\hline Average Relationship Strength & $\begin{array}{l}-0.386^{*} \\
(-1.89)\end{array}$ & $\begin{array}{l}-0.404^{* *} \\
(-1.98)\end{array}$ & $\begin{array}{l}6.778^{* * *} \\
-3.56\end{array}$ & $\begin{array}{c}8.256^{* * *} \\
-4.67\end{array}$ & $\begin{array}{l}-0.954 * * * \\
(-3.57)\end{array}$ \\
\hline Relational Divisive Faultlines & & $\begin{array}{c}0.090 * \\
-1.74\end{array}$ & & & $\begin{array}{l}0.106^{* *} \\
-2.07\end{array}$ \\
\hline Subgroup Structure & & & & $\begin{array}{l}2.517^{* * *} \\
-3.59\end{array}$ & \\
\hline Subgroup Structure*Subgroup Structure & & & & $\begin{array}{l}-0.366^{* *} \\
-2.41\end{array}$ & \\
\hline Position Embeddedness & & & & & $\begin{array}{l}0.256 * * * \\
-3.09\end{array}$ \\
\hline $\begin{array}{c}\text { Relational Divisive Faultlines*Position } \\
\text { Embeddedness }\end{array}$ & & & & & $0.022 *$ \\
\hline _cons & $\begin{array}{c}0.267^{* *} \\
-0.51\end{array}$ & $\begin{array}{c}0.175^{* *} \\
-0.34\end{array}$ & $\begin{array}{l}-12.192 * * \\
(-2.52)\end{array}$ & $\begin{array}{l}-9.371 * * \\
(-1.99)\end{array}$ & $\begin{array}{c}-0.72 \\
0.818^{* *} \\
-1.46\end{array}$ \\
\hline $\mathrm{N}$ & 221 & 221 & 221 & 221 & 221 \\
\hline $\mathrm{F}$ & 28.512 & 24.487 & 78.219 & 71.669 & 20.224 \\
\hline $\mathrm{R} 2$ & 0.399 & 0.407 & 0.645 & 0.702 & 0.635 \\
\hline$\triangle \mathrm{R} 2$ & & 0.026 & & 0.057 & 0.210 \\
\hline
\end{tabular}

Notes: Robust standard errors are shown in parentheses; ${ }^{* * *}, * *$ and ${ }^{*}$ represent $p<0.01, p<0.05$, and $p<0.1$, respectively.

(1) The influence of relational divisive faultlines on the subgroup structure.

Hypothesis 1 of this article is proposed. The relational divisive faultlines caused by the distribution of inter-organizational relations positively affects the structure of subgroups. This can be confirmed by the results of Model 2 in Table 4 . Relational divisive faultlines have a significant positive impact on the subgroups' structure $(\beta=0.090, p<0.1)$. The overall explained variation of the model increased by $2.6 \%$ compared to model $1(\triangle \mathrm{R} 2=0.026)$. Hypothesis 1 is verified.

(2) The influence of subgroup structure on agriculture technological innovation.

Hypothesis 2 of this article is proposed. The subgroup structure and agricultural technological innovation are in an inverted U-shaped relationship. Table 4 shows the results of Model 4. When all control variables are controlled, the subgroup structure significantly impacts technological innovation $(\beta=2.517, p<0.01)$. In addition, the square term of the subgroup structure has a significant negative impact on agriculture technological innovation $(\beta=-0.366, p<0.05)$. This shows that there is an inverted $U$-shaped relationship 
between the subgroup structure and agricultural technological innovation. The overall explained variation of the model increased by $5.7 \%$ compared with Model $1(\triangle \mathrm{R} 2=0.057)$. Hypothesis 2 is verified.

According to Model 4, we drew a diagram of the effect of the subgroup structure on agricultural technological innovation. Figure 2 shows that there is an inverted U-shaped relationship between subgroup structure and agricultural technological innovation. The results further support Hypothesis 2.

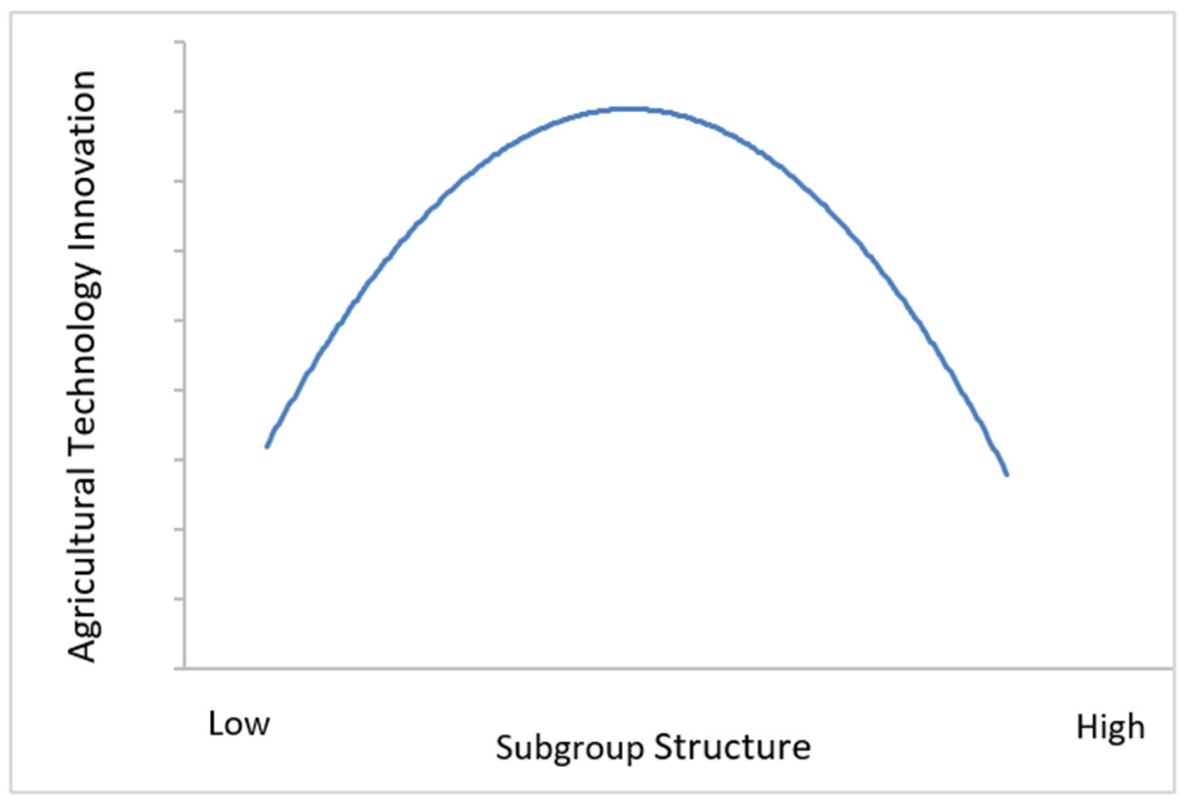

Figure 2. The Effect of the Subgroup Structure on Agricultural Technological Innovation.

(3) The moderating role of positional embeddedness.

Hypothesis 3 of this article is proposed. Positional embeddedness has a moderating effect between relational divisive faultlines and subgroup structure. An increased degree of dispersion of the overall network positional embeddedness means that the relational divisive faultlines have a stronger positive effect on the subgroup structure.

Table 4 shows the results of Model 5 . Positional embeddedness has a significant impact on the structure of subgroups $(\beta=-0.256, p<0.01)$. The interaction term between positional embeddedness and relational divisive faultlines has a positive effect on the subgroup structure $(\beta=0.022, p<0.1)$. The overall explained variation of the model increased by $21.0 \%$ compared with model $2(\triangle \mathrm{R} 2=0.210)$. This shows that the high positional embeddedness intensifies the influence of relational divisive faultlines on the subgroup structure. Hypothesis 3 is verified.

According to Model 5, we drew a diagram of the moderating effect of positional embeddedness on the relationship between relational divisive faultlines and subgroup structure. Figure 3 shows the case of embedding in a high position. The positive effect of relational divisive faultlines on the subgroup structure is significantly more notable than that of low-position embeddedness (larger slope). The results further support Hypothesis 3. 


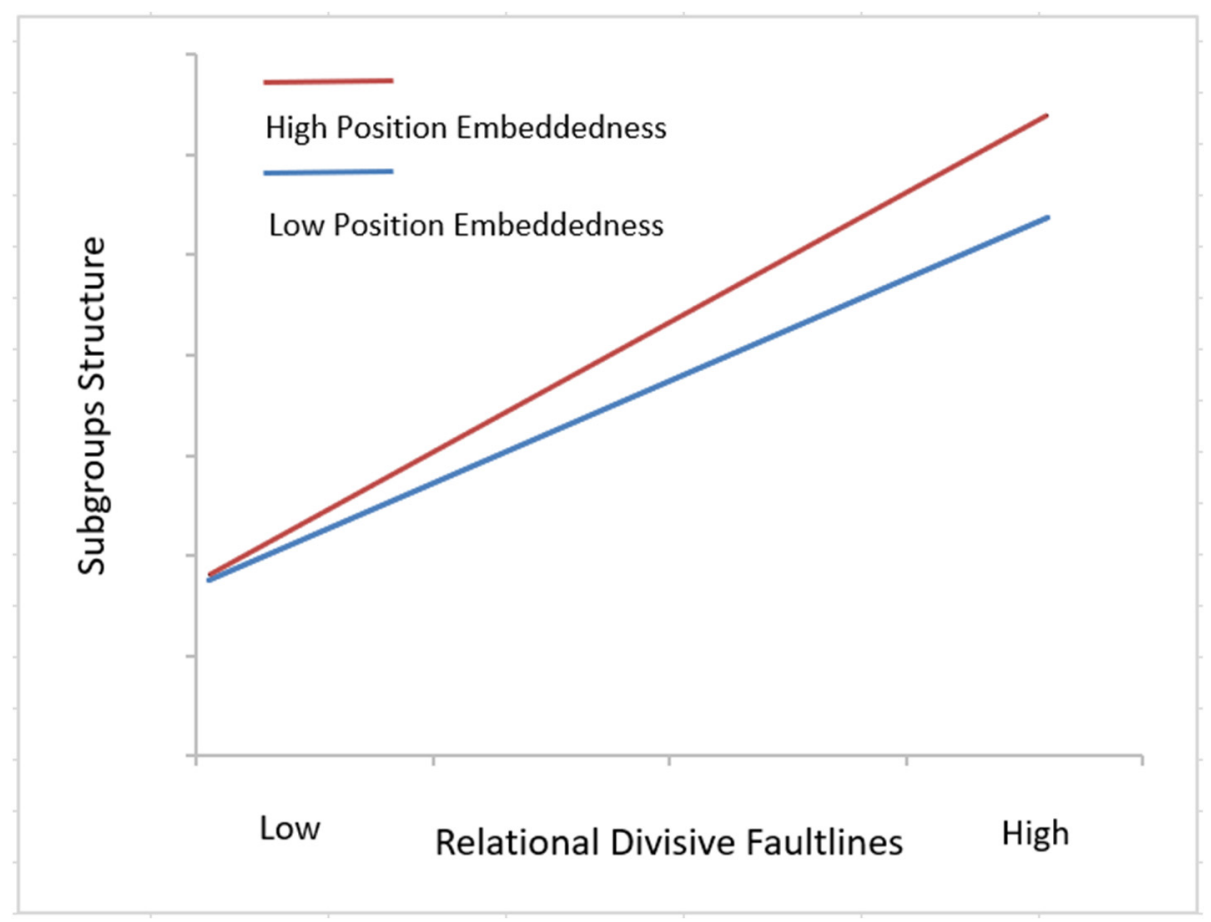

Figure 3. Interaction of Positional Embeddedness and Relational Divisive Faultlines on Subgroup Structure.

\subsection{Robustness Test}

In order to further determine the robustness of the regression results, this article uses variable substitution to test the robustness of the research hypothesis. The existing literature uses the duration of the relationship to measure the strength of the historical relationship between organizations in order to measure the relationship divisive faultlines further. In addition, the strength of historical relationships between organizations can also be measured by the number of collaborations [37]. Therefore, this article uses the number of collaborations to represent agricultural technological innovation for the robustness test. The number of joint applications for invention patents by member pairs $(\mathrm{k})$ in the past 5 years ( $t-5$ to $t-1)$ is used to measure the strength of historical relationships between organizations. To avoid a large number of low-quality and repeated patent applications affecting the measurement results, this article excludes the invention patents that have the same inventors and very similar patent names between the two organizations and only keeps one item to be included in the number of collaborations, similar to the previous article. Once we have calculated the number of joint patent applications of all members in the current time window, then we calculate the standard deviation to measure the relational divisive faultlines. Based on this method, after re-calculating the relational divisive faultlines and performing logarithmic processing, we replaced the previous relational divisive faultlines for regression analysis. The regression results are shown in Table 5.

It can be seen from the results of Model 2 in Table 5 that relational divisive faultlines have a significant positive impact on the structure of subgroups $(\beta=0.090, p<0.1)$. This is consistent with the previous empirical results. It shows that the Hypothesis 1 test results for divisive faultlines and subgroup structure are robust.

In Model 4 in Table 5 is the robustness test of the subgroup structure to agricultural technological innovation. The results of Model 4 are shown. The subgroup structure has a significant inverted U-shaped influence on agricultural technological innovation. The first term of the subgroup structure has a significant positive impact on agricultural technological innovation $(\beta=2.517, p<0.01)$. The square term of the subgroup structure has a significant negative impact on agricultural technological innovation $(\beta=-0.366$, 
$p<0.05)$. The result of Hypothesis 2 is still supported. It shows that the Hypothesis 2 test results of the subgroup structure on agricultural technological innovation are robust.

Table 5. The Results of Robustness Test after Changing the Indicators of Agricultural Technological Innovation.

\begin{tabular}{|c|c|c|c|c|c|}
\hline & $\begin{array}{l}\text { Subgroup } \\
\text { Structure }\end{array}$ & $\begin{array}{l}\text { Subgroup } \\
\text { Structure }\end{array}$ & $\begin{array}{c}\text { Agricultural } \\
\text { Technological Innovation }\end{array}$ & $\begin{array}{c}\text { Agricultural } \\
\text { Technological Innovation }\end{array}$ & $\begin{array}{l}\text { Subgroup } \\
\text { Structure }\end{array}$ \\
\hline Number of Subgroups & $\begin{array}{l}-0.755^{* * *} \\
(-11.01)\end{array}$ & $\begin{array}{l}-0.747^{* * *} \\
(-10.92)\end{array}$ & $\begin{array}{c}3.845^{* * *} \\
(6.02)\end{array}$ & $\begin{array}{l}6.412 * * * \\
(8.71)\end{array}$ & $\begin{array}{l}-0.684^{* * *} \\
(-9.67)\end{array}$ \\
\hline Network Density & $\begin{array}{l}0.322 \\
(1.02)\end{array}$ & $\begin{array}{l}0.301 \\
(0.96)\end{array}$ & $\begin{aligned}- & 14.712 * * * \\
& (-5.01)\end{aligned}$ & $\begin{aligned}-15.833 * * * \\
(-5.84)\end{aligned}$ & $\begin{array}{l}1.298^{* * *} \\
(2.84)\end{array}$ \\
\hline Network Size & $\begin{array}{l}2.959 * * * \\
(7.93)\end{array}$ & $\begin{array}{l}2.919 * * * \\
(7.85)\end{array}$ & $\begin{array}{l}4.761 \\
(1.37)\end{array}$ & $\begin{array}{l}-6.025 \\
(-1.65)\end{array}$ & $\begin{array}{l}2.670 * * * \\
(6.95)\end{array}$ \\
\hline Average Position Embeddedness & $\begin{array}{l}0.114 \\
(1.44)\end{array}$ & $\begin{array}{l}0.114 \\
(1.46)\end{array}$ & $\begin{array}{l}1.624^{* *} \\
(2.21)\end{array}$ & $\begin{array}{c}1.223 * \\
(1.80)\end{array}$ & $\begin{array}{l}-0.029 \\
(-0.31)\end{array}$ \\
\hline Average Relationship Strength & $\begin{array}{l}-0.386 * \\
(-1.89)\end{array}$ & $\begin{array}{l}-0.393 * \\
(-1.93)\end{array}$ & $\begin{array}{l}6.778^{* * *} \\
(3.56)\end{array}$ & $\begin{array}{l}8.256^{* * *} \\
(4.67)\end{array}$ & $\begin{array}{l}-0.934 * * * \\
(-3.50)\end{array}$ \\
\hline Relational Divisive Faultlines & & $\begin{array}{c}0.090 * \\
(1.75)\end{array}$ & & & $\begin{array}{l}0.104^{* *} \\
(2.03)\end{array}$ \\
\hline Subgroup Structure & & & & $\begin{array}{l}2.517 * * * \\
(3.59)\end{array}$ & \\
\hline Subgroup Structure*Subgroup Structure & & & & $\begin{array}{l}0.366^{* *} \\
(2.41)\end{array}$ & \\
\hline Position Embeddedness & & & & & $\begin{array}{l}0.253 * * * \\
(3.05)\end{array}$ \\
\hline $\begin{array}{c}\text { Relational Divisive Faultlines * Position } \\
\text { Embeddedness }\end{array}$ & & & & & $0.020 *$ \\
\hline -cons & $\begin{array}{l}0.267 \\
(0.51)\end{array}$ & $\begin{array}{l}0.098 \\
(0.19)\end{array}$ & $\begin{array}{c}-12.192 * * \\
(-2.52)\end{array}$ & $\begin{array}{l}-9.371 * * \\
(-1.99)\end{array}$ & $\begin{array}{l}(0.63) \\
0.718 \\
(1.27)\end{array}$ \\
\hline $\mathrm{N}$ & 221.000 & 221.000 & 221.000 & 221.000 & 221.000 \\
\hline $\mathrm{F}$ & 28.512 & 24.503 & 78.219 & 71.669 & 20.193 \\
\hline R2 & 0.399 & 0.431 & 0.645 & 0.702 & 0.639 \\
\hline$\triangle \mathrm{R} 2$ & & 0.032 & & 0.057 & 0.214 \\
\hline
\end{tabular}

Notes: Robust standard errors are shown in parentheses; ${ }^{* * *},{ }^{* *}$, and ${ }^{*}$ represent $p<0.01, p<0.05$, and $p<0.1$, respectively.

It can be seen from the results of Model 5 in Table 5 that positional embeddedness has a positive and significant effect on the subgroup structure $(\beta=-0.253, p<0.01)$. The interaction term between positional embeddedness and relational divisive faultlines has a positive effect on the subgroup structure $(\beta=0.020, p<0.1)$. The result of Hypothesis 3 is still supported. In summary, the empirical results show that the Hypothesis 3 testing of position embeddedness is robust.

\section{Discussion}

Consistent with previous studies [38], our results show that inter-organizational cooperation is an important factor affecting technological innovation; however, based on previous studies, the most important extension of this study is to analyze the relationship between the strength distribution of the binary relationship between organizations in the cooperation network and agricultural technological innovation. This article considers the influence of relational divisive faultlines caused by the strength distribution of binary relationships among organizations in cooperative networks. We find that the relational divisive faultlines affect agricultural technological innovation and food security by forming subgroup structure.

Compared with the existing literature [16,17], our results reflect the relationship between relational divisive faultlines and subgroup structure. The results show that the divisive faultlines caused by the uneven distribution of the strength of the binary relationship among organizations in the cooperative network significantly affect the subgroup structure. A possible explanation is that the uneven distribution of relationship intensity in the inter-organizational network will cause a difference in experience sharing among agricultural firms through direct social interaction [39]. Network members can more clearly perceive the similarities and differences between each other, resulting in "within group" 
and "outside group" subgroup problems. This kind of strong relationship within the group has strong path dependence and relationship inertia, which will make the local cohesiveness between firms stable for long periods, and is conducive to the stability of the subgroup structure.

Our results also reflect the relationship between subgroup structure and agricultural technological innovation. It is found that the influence of the subgroup structure in the inter-organizational cooperation network on agricultural technological innovation has two sides. On one hand, the formation of subgroups can promote the production of collective social capital. To protect the collective interests within the subgroup, it is easy for members to trust each other and form a normative consensus, which leads to strong social cohesion within the subgroup. This cohesion is conducive to the role of formal and informal governance mechanisms, which promotes knowledge sharing among firms and improves the performance of subgroup cooperative innovation [40]. It is found that subgroup structure positively impacts on agricultural technological innovation in the early stage of formation.

On the other hand, the structural isolation between subgroups will hinder technological innovation among subgroups. The formation of a subgroup structure means that "within group" and "outside group" problems are triggered. As a result, knowledge and information flow tend to flow within subgroups rather than among subgroups. This reduces the strength of knowledge transfer, trade, and absorption among subgroups [41]. It is found that the formation of subgroup structure leads to the obstruction of information flow among subgroups, which has a negative impact on agricultural technological innovation.

Compared with the existing literature [22], it is also found that the position embeddedness of agricultural firms has a moderating effect between the divisive faultlines and the subgroup structure. In a network with a high degree of position embeddedness, the central position firms use their information advantages, reputation advantages, and status advantages [21,42]. This can promote the cohesiveness of the local network and reduce opportunistic behavior, and coordinate and manage the relationship between firms. The central position of firms can make the cooperation between firms around them closer. It enhances the stability of the central/peripheral network structure. Therefore, it is easier to form a strong relationship centered sub group in the case of highly discrete position embeddedness.

\section{Conclusions}

Agricultural technological innovation is an important guarantee to ensuring food security. At the same time, the government proposes that it should increase investment in agricultural research, promote the broad application of science and technology in agriculture, and promote the innovation of agricultural technology to advance the transformation of traditional agriculture to modern agriculture. In addition, much research has been done on the influencing factors of technological innovation, and few scholars have discussed agricultural technological innovation from the perspective of networks. This article explores how the distribution of binary relationship among network members affects agricultural technological innovation from the perspective of inter-organizational networks. Agricultural technology patents were downloaded from the Derwent patent database, and multiple linear regression was used to test hypotheses. The empirical results show that the direct influence of relational divisive faultlines on subgroup structure is significant. The inverted U-shaped relationship between subgroup structure and agricultural technological innovation is significant; that is, subgroup structure has a positive impact on agricultural technological innovation in the early stage of its formation, and with the formation of subgroup structure, information flow among subgroups is hindered, which has a negative impact on agricultural technological innovation. Position embeddedness has a moderating effect between network faultlines and subgroup structure formation.

The research results provide meaningful guidance for firms in the process of cooperation. As the main body of agricultural technological innovation, firms should fully realize that technological innovation is the core competitive and driving force of sustain- 
able development. To improve innovation efficiency, many firms or organizations form a network through cooperation. The cooperation network of many organizations is like a huge knowledge pool which can provide an essential foundation for firms to access new knowledge for technological innovation. In the process of cooperation, firms should pay attention to the following aspects.

First, when agricultural firms participate in the initial stage of an agricultural technological innovation cooperation network to enhance the possibility of acquiring heterogeneous knowledge, they should cooperate and exchange with closely related agricultural firms as far as possible to obtain convenient conditions for technological innovation from many aspects, such as innovation atmosphere, innovation resources, laws and regulations, and the evaluation of technological innovation achievements. This stimulates the innovation vitality of firms and ensures the technological innovation ability of agricultural firms.

Second, in cooperation, the partner selection preference of the organization members makes the agricultural technological innovation network appear to have a certain degree of local cohesion. Next form subgroups. When the agricultural cooperation network begins to appear in some local subgroups, the information exchange among the subgroups becomes more frequent, which is conducive to the establishment of a strong trust mechanism between agricultural firms and the improvement of knowledge sharing and absorption. At the same time, the appropriate bridging relationship between subgroups introduces the heterogeneous knowledge and resources of different subgroups, and absorbs them through the strong interaction between the members of the subgroups.

Finally, the agricultural firms in the central position can make the cooperation between agricultural firms closer. On one hand, this can promote the stability of the cooperation between agricultural firms and enhance the strength of the relationship between the agricultural technological cooperation network members. This improves the knowledge absorption capacity of agricultural firms, and solves the "action problem" of coordination and governance in agricultural technological innovation networks, On the other hand, it can alleviate the uncertainty risk of cooperation with diverse partners. By contacting and attracting novelty knowledge and information, we can solve the "creative problems" of technological innovation partners.

On the whole, this article has certain theoretical innovations and practical significance. However, this article also has certain limitations. First, the measurement method in this article has certain constraints. The entry and exit of network members will cause fluctuations in the size of the network. This also brings difficulties to the division of network boundaries and affects the measurement results of variables. Second, this article does not consider factors that can influence the partner selection process-for example, the cognition, attitude, and preference of firms as actors. Future research could be considered from the following aspects to explore the influence of key nodes on the effect of divisive faultlines. To a large extent, divisive faultlines affect the results of the network operation by causing subgroup problems "within the group" and "outside the group". This impact has both positive and negative sides. Solving this subgroup problem and highlighting its positive role and restraining its negative role has become a breakthrough in tackling the effect of divisive faultlines.

Author Contributions: Conceptualization, L.C. and X.L.; methodology, S.Z. and J.H.; software, F.R. and R.B.; formal analysis, S.Z. and L.C.; resources, R.B. and J.H.; writing-original draft preparation, F.R.; writing-review and editing, L.C., J.H., S.Z. and F.R. All authors have read and agreed to the published version of the manuscript.

Funding: Grant-in-aid supported this work for scientific research from the National Natural Science Foundation for the Youth of China (No. 72002170), (Ministry of Education in China) Project of Humanities and Social Sciences (No.20YJC630010), Shaanxi Province Philosophy and Social Science Key Research Base Project of China (No. 20JZ090). Project of Shaanxi Provincial Department of Education (18JK0696), Social Science Foundation of Shaanxi Province (2020R009), annual general project on major theoretical and practical issues of philosophy and Social Sciences in Shaanxi Province (2021ND0348), key research base project of philosophy and social sciences of Shaanxi Provincial 
Department of Education(18JZ053), Shaanxi Province Soft Science Research Program General Project of China (No. 2020KRM027), Xi'an University of Posts and Telecommunications Innovation Fund of China (No. CXJJWZ2019002).

Data Availability Statement: The data presented in this study are available on request from the corresponding author.

Conflicts of Interest: The authors declare that they have no conflicts of interest.

\section{References}

1. Yin, C. Grain development and food security in post epidemic era. Issues Agric. Econ. 2021, 4-13. [CrossRef]

2. Sun, H.; Zhang, Y. Problems and countermeasures of China's grain trade from the perspective of food security. Grain Issues Res. 2020, 13-16.

3. Gulati, R.; Sytch, M.; Tatarynowicz, A. The rise and fall of small worlds: Exploring the dynamics of social structure. Organ. Sci. 2012, 23, 449-471. [CrossRef]

4. Heidl, R.A.; Steensma, H.K.; Phelps, C. Divisive faultlines and the unplanned dissolutions of multipartner alliances. Organ. Sci. 2014, 25, 1351-1371. [CrossRef]

5. Lau, D.C.; Murnighan, J.K. Interactions within groups and subgroups: The effects of demographic faultlines. Acad. Manag. J. 2005, 48, 645-659. [CrossRef]

6. Thatcher, S.M.; Jehn, K.A.; Zanutto, E. Cracks in diversity research: The effects of diversity faultlines on conflict and performance. Group Decis. Negot. 2003, 12, 217-241. [CrossRef]

7. Sytch, M.; Tatarynowicz, A. Exploring the locus of invention: The dynamics of network communities and firms' invention productivity. Acad. Manag. J. 2014, 57, 249-279. [CrossRef]

8. Coleman, J.S. Social capital in the creation of human capital. Am. J. Sociol. 1988, 94, 95-120. [CrossRef]

9. Clement, J.; Shipilov, A.; Galunic, D.C. Brokerage as a public good: The externalities of network hubs for different formal roles in creative organizations. Adm. Sci. Q. 2018, 63, 251-286. [CrossRef]

10. Shipilov, A.V.; Li, S.X.; Greve, H.R. The prince and the pauper: Search and brokerage in the initiation of status-heterophilous ties. Organ. Sci. 2011, 22, 1418-1434. [CrossRef]

11. Lau, D.C.; Murnighan, J.K. Demographic diversity and faultlines: The compositional dynamics of organizational groups. Acad. Manag. Rev. 1998, 23, 325-340. [CrossRef]

12. Perry-Smith, J.E.; Shalley, C.E. A social composition view of team creativity: The role of member nationality-heterogeneous ties outside of the team. Organ. Sci. 2014, 25, 1434-1452. [CrossRef]

13. Zollo, M.; Reuer, J.J.; Singh, H. Interorganizational routines and performance in strategic alliances. Organ. Sci. 2002, 13, 701-713. [CrossRef]

14. Zhao, H.; Wang, H. Impact of R\&D alliance network structure on the competitive advantage of high and new technology enterprises. Sci. Res. Manag. 2013, 34, 143-152.

15. Arino, A.; De La Torre, J. Learning from failure: Towards an evolutionary model of collaborative ventures. Organ. Sci. 1998, 9 , 306-325. [CrossRef]

16. Yang, S.; Hexmoor, H. Measuring optimal connections in large networks: A new algorithm and its applications. J. Math. Sociol. 2004, 28, 197-213. [CrossRef]

17. Dang, X.; Cheng, L. Impact of technological innovation network divisive faultlines on subgroup polarization:Based on network embeddedness perspective. Stud. Sci. Sci. 2016, 34, 781-792.

18. Gulati, R.; Nohria, N.; Zaheer, A. Strategic networks. Strateg. Manag. J. 2000, 21, 203-215. [CrossRef]

19. Gulati, R. Social structure and alliance formation patterns: A longitudinal analysis. Adm. Sci. Q. 1995, 40, 619-652. [CrossRef]

20. Ahuja, G. Collaboration networks, structural holes, and Innovation: A longitudinal study. Adm. Sci. Q. 2000, 45, 425-455. [CrossRef]

21. Podolny, J.M. Market uncertainty and the social character of economic exchange. Adm. Sci. Q. 1994, 39, 458-483. [CrossRef]

22. Yang, H.; Lin, Z.J.; Lin, Y.L. A multilevel framework of firm boundaries: Firm characteristics, dyadic differences, and network attributes. Strateg. Manag. J. 2010, 31, 237-261. [CrossRef]

23. Che, Y.; Li, M. Analysis of patent technique base on derwent manual codes-Taking the case of wind energy. Inf. Sci. 2015, 33, 132-138.

24. Hua, Z.; Xiangqian, Z. How actors hold the structural hole position: The constraints and incentives embedded in network structure and network content. Manag. Rev. 2014, 89-98. [CrossRef]

25. Chemmanur, T.J.; Elena, L.; Xuan, T. Corporate venture capital, value creation, and innovation. Narnia 2014, $27,2434-2473$. [CrossRef]

26. Tian, X.; Wang, T. Tolerance for failure and corporate innovation. Rev. Financ. Stud. 2014, 27, 211-255. [CrossRef]

27. Liu, Y.; Ji, D.; Zhang, L.; An, J.; Sun, W. Rural financial development impacts on agricultural technology innovation: Evidence from China. Int. J. Environ. Res. Public Health 2021, 18, 1110. [CrossRef]

28. Gibson, C.; Vermeulen, F. A healthy divide: Subgroups as a stimulus for team learning behavior. Adm. Sci. Q. 2003, 48, 202-239. [CrossRef] 
29. Rogan, M. Too close for comfort? The effect of embeddedness and competitive overlap on client relationship retention following an acquisition. Organ. Sci. 2014, 25, 185-203. [CrossRef]

30. Wensheng, H.; Linbin, X. Research on the types and structural characteristics of private hotel employees' social networks-Based on the perspective of centrality and agglomerative subgroups. Enterp. Econ. 2020, 87-94. [CrossRef]

31. Yan, Z.; Weiyu, F.; Xiangiie, Z. The impact of coupling between cliques and knowledge flow in alliance network on firm innovation capability. Sci. Res. Manag. 2016, 37, 51-58.

32. Yan, Z.; Qingshi, M. Evaluation of enterprise innovative capability based on cohesive behaviors in inter-firm innovation network. Sci. Res. Manag. 2014, 35, 35-43.

33. Gulati, R.; Singh, H. The architecture of cooperation: Managing coordination costs and appropriation concerns in strategic alliances. Adm. Sci. Q. 1998, 43, 781-814. [CrossRef]

34. Oh, H.; Chung, M.-H.; Labianca, G. Group social capital and group effectiveness: The role of informal socializing ties. Acad. Manag. J. 2004, 47, 860-875. [CrossRef]

35. Liu, D.; Zhou, H. Research on fluctuation of rice price based on multiple linear research on fluctuation of rice price based on multiple linear. Prices Mon. 2017, 9, 1-6.

36. Song, S.; Qi, W. Research on the transfer of rural surplus labor force based on multiple linear regression - Evidence from Heilongjiang Province. J. Agrotech. Econ. 2014, 4, 104-110.

37. Reuer, J.J.; Lahiri, N. Searching for alliance partners: Effects of geographic distance on the formation of R\&D collaborations. Organ. Sci. 2014, 25, 283-298.

38. Yang, L.; Zeng, D.; Zou, S.; Zhao, S. A study of scientific collaboration network, knowledge diversity and firm innovation. Stud. Sci. Sci. 2021, 39, 867-875.

39. Mayer, K.J.; Argyres, N.S. Learning to contract: Evidence from the personal computer industry. Organ. Sci. 2004, 15, 394-410. [CrossRef]

40. Ozer, M.; Zhang, W. The effects of geographic and network ties on exploitative and exploratory product innovation. Strateg. Manag. J. 2015, 36, 1105-1114. [CrossRef]

41. Boschma, R. Proximity and innovation: A critical assessment. Reg. Stud. 2005, 39, 61-74. [CrossRef]

42. Cuevas, J.M.; Julkunen, S.; Gabrielsson, M. Power symmetry and the development of trust in interdependent relationships: The mediating role of goal congruence. Ind. Mark. Manag. 2015, 48, 149-159. [CrossRef] 